\title{
ФАКТОРЫ ПОВЫШЕНИЯ КОНКУРЕНТОСПОСОБНОСТИ ПРОИЗВОДСТВЕННОГО ПОТЕНЦИАЛА АГРОПРОМЫШЛЕННОГО КОМПЛЕКСА В ЦЕПОЧКАХ ДОБАВЛЕННОЙ СТОИМОСТИ
}

\author{
(C) 2021 Васильченко Марианна Яковлевна \\ кандидат экономических наук, старший научный сотрудник \\ Институт аграрных проблем Российской академии наук, Россия, Саратов \\ E-mail: mari.vasil4enko@yandex.ru
}

\begin{abstract}
Одним из условий устойчивого развития производственного потенциала агропромышленного комплекса является повышение конкурентоспособности отраслей, отдельных видов деятельности и звеньев в цепочках создания добавленной стоимости. Создаваемая в сельском хозяйстве валовая добавленная стоимость значительно ниже, чем в других отраслях экономики, что объясняется высокой стоимостью производственных ресурсов вследствие наличия значительной доли импортных компонентов в составе материальных затрат. В статье исследованы конкурентные возможности агропромышленного комплекса на внутреннем и мировом рынках. Представлена оценка возможностей увеличения добавленной стоимости в отдельных продуктовых цепочках. Проведен SWOT-aнализ по отдельным отраслям и цепочкам животноводческого подкомплекса России для выявления возможностей роста конкурентоспособности в краткосрочной и долгосрочной перспективе. Рассмотрены меры государственной поддержки реализации конкурентных преимуществ отраслей животноводческого подкомплекса.
\end{abstract}

Ключевые слова: агропромышленный комплекс, животноводство, конкурентоспособность, производственный потенциал, SWOT-анализ, государственная поддержка

\section{Введение}

Устойчивое развитие производственного потенциала агропромышленного комплекса в условиях нарастания внешнеэкономических рисков может быть достигнуто в результате динамичного роста его конкурентоспособности.

Одним из приоритетных направлений экономической политики России является расширение интеграции обрабатывающих отраслей в мировую экономику на основе их встраивания в глобальные цепочки производства добавленной стоимости и поддержка экспорта продукции с высокой долей добавленной стоимости. Это позволит повысить конкурентоспособность продукции на внутреннем и внешнем рынках, что особенно актуально для отечественного агропромышленного комплекса. В настоящее время создаваемая в сельском хозяйстве валовая добавленная стоимость значительно ниже, чем в других отраслях экономики, что является долговременной тенденцией. Согласно расчетам, производство валовой добавленной стоимости в сельском хозяйстве в расчете на одного работника ниже в 6-7 раз по сравнению с остальными отраслями экономики. В 2018 г. валовая добав- ленная стоимость по виду деятельности «растениеводство и животноводство, охота и предоставление услуг в той области» составила 2883,4 млрд. руб. или 3,1\% от ВВП, снизившись по сравнению с 2014 г. на 0,4 процентных пункта.

Конкурентоспособность отдельных звеньев продуктовых цепочек зависит от качества продукции; ценовых и затратных факторов; степени глубины переработки и уровня диверсификации производства. самообеспечения промежуточными и конечными продуктами, результативности государственной поддержки.

Результаты исследования.

В целях осуществления систематизации факторов конкурентоспособности различных видов животноводческой продукции был проведен SWOT-анализ по отдельным отраслям и цепочкам животноводческого подкомплекса России для выявления возможностей роста конкурентоспособности в краткосрочной и долгосрочной перспективе. Эмпирическим путем с использованием результатов предыдущих исследований и экспертных оценок была дана оценка конкурентоспособности цепочек добавленной стоимости в животноводческом подкомплексе. 
Таблица 1. SWOT-анализ конкурентоспособности продуктовых цепочек животноводческого подкомлекса *

\begin{tabular}{|c|c|c|c|}
\hline Сильные стороны & Слабые стороны & Возможности & Угрозы \\
\hline \multicolumn{4}{|c|}{ 1. Производство молока и молочных продуктов } \\
\hline $\begin{array}{l}\text { Диверсификация про- } \\
\text { дукции переработки }\end{array}$ & $\begin{array}{l}\text { Сезонность производства } \\
\text { молока. } \\
\text { Кормовая несбалан- } \\
\text { сированность. Низкая } \\
\text { конкуренто-способность } \\
\text { по уровню издержек и } \\
\text { качеству промежуточной } \\
\text { и конечной продукции. } \\
\text { Низкий уровень товарно- } \\
\text { сти молока. } \\
\text { Низкая добавленная } \\
\text { стоимость производства и } \\
\text { переработки. } \\
\text { Низкие ценовые конку- } \\
\text { рентные преимущества на } \\
\text { международном рынке. }\end{array}$ & $\begin{array}{l}\text { Внедрение цифровых тех- } \\
\text { нологий производства. } \\
\text { Возможности для насы- } \\
\text { щения внутреннего рынка } \\
\text { продукцией собственного } \\
\text { производства. } \\
\text { Снижение импортной } \\
\text { зависимости на рынке } \\
\text { высокоэнергетических } \\
\text { кормов } \\
\text { (в том числе на соевые, } \\
\text { рапсовые шрота и жмыхи, } \\
\text { комбикорма). } \\
\text { Использование отходов } \\
\text { для получения микробио- } \\
\text { логически переработан- } \\
\text { ных и ферментированных } \\
\text { кормовых добавок. } \\
\text { Снижение удельной ре- } \\
\text { сурсоемкости конечного } \\
\text { продукта. } \\
\text { Развитие переработки с } \\
\text { внедрением инновацион- } \\
\text { ного оборудования. }\end{array}$ & $\begin{array}{l}\text { Низкий уровень распро- } \\
\text { странения инноваций на } \\
\text { стадии производства. } \\
\text { Замедление темпов роста } \\
\text { вследствие институци- } \\
\text { ональ-ной неоднород- } \\
\text { ности произво-дителей } \\
\text { молока. } \\
\text { Высокий уровень конку- } \\
\text { ренции на международ- } \\
\text { ном } \\
\text { рынке. Несоответствие } \\
\text { качества продукции экс- } \\
\text { портному спросу. }\end{array}$ \\
\hline \multicolumn{4}{|c|}{ 2. Производство мяса КРС, включая первичную переработку } \\
\hline $\begin{array}{l}\text { Высокие требования к } \\
\text { качеству готовой про- } \\
\text { дукции }\end{array}$ & $\begin{array}{l}\text { Низкий уровень внутрен- } \\
\text { него спроса на продукцию } \\
\text { специализированного } \\
\text { мясного скотоводства из- } \\
\text { за высоких цен. } \\
\text { Неудовлетворительное } \\
\text { состояние естественных } \\
\text { кормовых угодий. }\end{array}$ & $\begin{array}{l}\text { Снижение импортной } \\
\text { зависимости на рынке } \\
\text { генетического материала. } \\
\text { Наращивание экспорт- } \\
\text { ного } \\
\text { потенциала отрасли. } \\
\text { Повышение адаптивности } \\
\text { отрасли селекции к кли- } \\
\text { матическим изменениям. }\end{array}$ & $\begin{array}{l}\text { Высокий уровень конку- } \\
\text { ренции на международ- } \\
\text { ном } \\
\text { рынке. }\end{array}$ \\
\hline \multicolumn{4}{|c|}{ 3. Производство мяса свиней, включая первичную переработку } \\
\hline $\begin{array}{l}\text { Высокий уровень техно- } \\
\text { логической модерниза- } \\
\text { ции. } \\
\text { Ценовая конкурентоспо- } \\
\text { собность на междуна- } \\
\text { родном рынке. } \\
\text { Соответствие мировому } \\
\text { уровню по отдельным } \\
\text { видам затрат } \\
\text { Высокие темпы роста } \\
\text { производства и продук- } \\
\text { тивности }\end{array}$ & $\begin{array}{l}\text { Низкие показатели вос- } \\
\text { производства стада }\end{array}$ & $\begin{array}{l}\text { Внедрение цифровых } \\
\text { технологий кормопро- } \\
\text { изводства. Наращивание } \\
\text { экспортного } \\
\text { потенциала отрасли. } \\
\text { Снижение импортной } \\
\text { зависимости на рынке } \\
\text { белковых кормов, вита- } \\
\text { минов, ферментов, } \\
\text { ветеринарных } \\
\text { препаратов, витаминов. }\end{array}$ & $\begin{array}{l}\text { Перепроизводство на } \\
\text { внутреннем рынке и } \\
\text { снижение покупательской } \\
\text { способности населения. } \\
\text { Высокие экологические } \\
\text { риски. Неблагоприятная } \\
\text { эпизоотическая обста- } \\
\text { новка для производства в } \\
\text { хозяйствах населения } \\
\text { Торговые ограничения на } \\
\text { международном рынке. }\end{array}$ \\
\hline \multicolumn{4}{|c|}{ 4. Производство мяса птицы, включая первичную переработку } \\
\hline $\begin{array}{l}\text { Высокий уровень техно- } \\
\text { логической модерниза- } \\
\text { ции. } \\
\text { Ценовая конкурентоспо- } \\
\text { собность на междуна- } \\
\text { родном рынке. }\end{array}$ & $\begin{array}{l}\text { Региональная дифферен- } \\
\text { циация производства }\end{array}$ & $\begin{array}{l}\text { Снижение импортной } \\
\text { зависимости на рынке } \\
\text { белковых кормов, вита- } \\
\text { минов, ферментов, } \\
\text { ветеринарных } \\
\text { препаратов, генетическо- } \\
\text { го материала. Наращива- } \\
\text { ние экспортного } \\
\text { потенциала отрасли. } \\
\text { Диверсификация произ- } \\
\text { водства конечной продук- } \\
\text { ции. }\end{array}$ & $\begin{array}{l}\text { Высокие экологические } \\
\text { риски. } \\
\text { Торговые ограничения на } \\
\text { международном рынке. }\end{array}$ \\
\hline
\end{tabular}

* Составлено с использованием данных Федеральной статистики, монографического метода и экспертных оценок. 
Результаты анализа показали различные факторы формирования конкурентоспособности в отдельных продуктовых цепочках. По отдельным видам агропродовольственной продукции российские товаропроизводители обладают ценовым конкурентным преимуществом по сравнению с крупными экспортерами на мировом рынке. Это относится как к зерновым культурам, так и к продукции животноводства. Например, в 2018 г. в России стоимость одной тонны мяса птицы в среднем составляла 1037 долл. США, а в США - 1029 долл. Экспортные цены свинины в России достигли уровня 2024 долл. США за т; в США - 2535 долл. за т; в Германии - 2466 долл. за т. Однако цены российских производителей на молоко и молочную продукцию, а также мясо крупного рогатого скота выше, чем у основных экспортеров рассматриваемых видов продукции.

Вместе с тем показатели качества и ресурсоемкости заметно различаются при рассмотрении отдельных продуктов.

В молочном скотоводстве в силу точечного характера эффекта масштаба уровень издержек и качество продукции не соответствуют критериям конкурентоспособности, что связано с неоднородной институциональной средой; недостаточным распространением инноваций, особенно в малых предприятиях. Опыт таких регионов как Вологодская и Калужская области свидетельствует о достижении высокой конкурентоспособности в результате использования робототехники в фермерских хозяйствах [1]. Другие авторы отмечают в качестве ограничительных факторов роста конкурентоспособности животноводства высокие технологические риски, низкое качество кормовых ресурсов [2]; низкое качество молочного сырья [3]. По оценкам Национального союза производителей молока, за последние два года рост себестоимости производства молока существенно опережает темпы роста цен на сырое молоко и потребительских цен на готовую молочную продукцию [4]. Данная тенденция сохраняется и в 2021 году: из-за подорожания большинства статей затрат в марте 2021 года (в том числе на комбикорма, рапсовые шроты и жмыхи,), себестоимость производства молока была выше по сравнению с анализируемым периодом прошлого года на 18,2\%, а цены молочных продуктов возросли на 1-5\% [5].

Предыдущими исследованиями молочного подкомплекса в региональном разрезе выявле- но, что на стадии производства молока большую роль играет повышение продуктивности и степени товарности молока, а на стадии переработки значительна роль глубины переработки молока [6]. Сложившаяся институциональная структура производства продукции молочного скотоводства не позволяет заметно улучшить конкурентные позиции молочной продукции на мировом рынке, поскольку использование инновационных технологий в производстве молока имеет ярко выраженную региональную специфику, что не позволяет достигнуть среднегодового надоя молока на уровне европейских стран. По данным международной статистики средний надой молока на корову в странах ЕC-27 в 2019 году составил 7346 кг; в России - 6492 кг.

Перспективным направлением повышения конкурентоспособности продукции, особенно с позиций качества, является система точного животноводства. Согласно оценке экспертов молочного рынка, автоматизированные системы откорма, дойки и мониторинга здоровья поголовья скота позволяют повысить надои на 30-40\% [7].

Наибольший рост производства наблюдается в свиноводческой отрасли, что связано с реализацией инвестиционных проектов и расширением экспортных возможностей. По оценкам специалистов Национального Союза свиноводов, ежегодный прирост производства сохранится на уровне от 3 до 5\%, а к 2025 году производство достигнет 5,8 млн. т в живом весе. Основной прирост производства свиней на убой достигнут на вновь построенных и модернизированных комплексах и свинофермах.

Исследование зарубежного опыта позволило сделать вывод о сопоставимости показателей затрат кормов, труда, электроэнергии на производство свинины в России и развитых зарубежных странах. Вместе с тем Россия значительно уступает ведущим странам по показателям воспроизводства стада [8]. Полагаем, что данную проблему следует рассматривать в контексте спросовых ограничений на внутреннем рынке и возможностей расширения экспортных поставок, поскольку искусственное перепроизводство на внутреннем рынке может привести к отрицательному эффекту масштаба с дальнейшим ростом себестоимости продукции и одновременным снижением цен реализации.

Кроме того, в данной продуктовой цепочке наиболее ощутимы экологические проблемы 
вследствие высокой антропогенной нагрузки производства мяса. В целях стимулирования участия предприятий в природоохранных мероприятиях необходимо разработать специальную методику научно обоснованного учета выбросов в окружающую среду животноводческих ферм, установить лимиты на их размещение для конкретных предприятий и тарифы платы за загрязнение окружающей среды, а также определить порядок расчета налоговых вычетов в случае выполнения природоохранных мероприятий [9].

Тенденции снижения затрат производственных ресурсов и, соответственно, увеличения добавленной стоимости в краткосрочной и среднесрочной перспективе при условиях благоприятной конъюнктуры на внутреннем и внешнем рынках можно ожидать в продуктовых цепочках мяса свинины и птицы преимущественно за счет эффекта масштаба, хотя наличие высокой импортной компоненты по отдельным видам комбикормов и кормовых добавок остается значительным затратообразующим фактором, ограничивающим достижение ресурсной независимости аграрного производства [10].

Перспективы увеличения валовой добавленной стоимости в сельском хозяйстве связаны с технической и технологической модернизацией, преобразованиями в области селекции и семеноводства на основе стимулирования использования высокопродуктивных сортов сельскохозяйственных культур и пород животных. Предполагается развитие мощностей хранения и переработки сельхозсырья для увеличения доли продукции с высокой добавленной стоимостью; строительство современных оптовораспределительных центров и переработка продукции с внедрением инновационного оборудования. В зерновом производстве достаточно активно осуществляются меры, способствующие росту. добавленной стоимости: объемы промышленной глубокой переработки зерна в 2019 г. увеличились на 9,4\% по сравнению с 2018 г. и составили 2,5 млн. т. [11]. Реализация вышеуказанных направлений позволит увеличить производство добавленной стоимости агропромышленного комплекса к 2030 году до 7 трлн. руб.

Для оценки внутренней конкурентоспособности продукции необходимо выявление причинно-следственной зависимости между изменениями цен на отдельные компоненты сельскохозяйственного сырья и конечную про- дукцию; определение возможностей снижения издержек за счет внедрения инновационных технологий по всей цепочке производства добавленной стоимости и замещения импортных сырьевых компонентов.

Рейтинг факторов повышения конкурентоспособности АПК России на мировом рынке в 2018-2019 гг. отражает в качестве одного из приоритетных факторов государственную поддержку $(0,89)$. На втором месте находится стабильность законодательной политики, $(0,86)$ и на третьем - повышение производственнотехнического потенциала $(0,86)$. Равные позиции занимают такие факторы как снижение стоимости энергетических ресурсов $(0,81)$ и сокращение затрат $(0,81)$ [12]. Таким образом, снижение затрат на производство продолжает оставаться важным фактором, обеспечивающих рост конкурентоспособности продукции. Немаловажная роль отводится цифровизации сельского хозяйства, обеспечивающей повышение эффективности производства за счет снижения издержек и сокращения потерь. В современных условиях данное направление технологической перестройки агропромышленного комплекса имеет особую важность для молочного скотоводства.

В качестве мер, способствующих повышению конкурентоспособности продукции, следует отметить выделение субсидий на экспорт продуктов животного происхождения; развитие органического животноводства.

Отдельные формы государственной поддержки направлены на компенсацию производственных затрат. В настоящее время продолжает действовать такая форма господдержки как компенсация части понесенных капитальных затрат (CAPEX) при строительстве или модернизации молочных ферм. Данная мера распространяется также для поддержки строительства селекционно-гибридных центров, питомников, овощехранилищ, а также предприятий по производству детского питания. Начиная с 2021 года, предусмотрена такая форма господдержки как компенсация снижения цен производителям на значимые группы товаров. Важной мерой поддержки формирования конкурентных преимуществ отраслей животноводческого подкомплекса может служить снижение ставок по налогам на прибыль для предприятий, производящих машины и оборудование для животноводства, а также кормовые и ветеринарные препараты. 


\section{Библиографический список}

1. Суровцев В.Н., Бильков В. А., Никулина Ю. Н. Инновационное развитие молочного животноводства на СевероЗападе РФ как основа повышения конкурентоспособности производства молока // Экономические и социальные перемены: факты, тенденции, прогноз. 2013. № 4 (28). С. 143-150.

2. Рау В.В.,. Скульская Л.В.,. Широкова Т. К. Тенденции и факторы изменения ресурсоемкости аграрого сектора // Проблемы прогнозирования. 2013. № 4 (139). С. 55-66.

3. Кремянская Е.В., Кремянский В.Ф., Кремянский В.В. Ключевые факторы повышения эффективности и конкурентоспособности производства молока // Вестник Курской государственной сельскохозяйственной академии.2017. № 6. С. 76-80.

4. Карабут Т.Эксперты обеспокоены ростом себестоимости производства молока.URL:https://rg.ru/2021/04/28/ eksperty-obespokoeny-rostom-sebestoimosti-proizvodstva-moloka.html.

5. Себестоимость производства молока в 2020 году выросла на 18\%. URL: https://milknews.ru/analitika-rinkamoloka/indeks-rmsi/sebestoimost-moloko-2020.html.

6. Андрющенко С.А., Васильченко М.Я., Трифонова Е.Н. Факторы повышения эффективности производствен ного потенциала молочного скотоводства и молочной промышленности России // Аграрный научный журнал. 2018. № 5. С. 59-66.

7. Федоров А.Д., Кондратьева О.В. О перспективах цифровизации животноводства // Вестник Всероссийского научно-исследовательского института механизации животноводства. 2019. № 1 (33). С. 127-131.

8. Цой Л. М. Повышение эффективности производства свинины в России // Вестник Всероссийского научноисследовательского института механизации животноводства. 2012. № 3. С. 4-14.

9. Андрющенко С.А., Васильченко М. Я. Ресурсные возможности реализации реализации стратегии импортозамещения с учетом экологической ответственности агробизнеса // Аграрный научный журнал. 2014 . № 11. C. $75-80$.

10. Потапов А.П. Обеспечение ресурсной независимости аграрного производства в контексте продовольственной безопасности России // Проблемы прогнозирования. 2019. № 5. С. 120-129.

11. Национальный доклад « О ходе и результатах реализации в 2019 году государственной программы развития сельского хозяйства и регулирования рынков сельскохозяйственной продукции, сырья и продовольствия». URL: https://www.dairynews.ru/news-image/Natsdoklad2020.pdf.

12. Обзор рынка сельского хозяйства. URL: https://docviewer.yandex.ru/view/130929660/?page. 